Первый Московский государственный медииинский университет им. И.М. Сеченова

\title{
Восстановление речи после инсульта
}

\author{
Д.А. Гришина, к.м.н. \\ Адрес для переписки: Динара Александровна Гришина, dstepkina@mail.ru
}

Для цитирования: Грищина Д.А. Восстановление речи после инсульта // Эффективная фармакотерапия. 2019. Т. 15. № 34. С. $20-25$. DOI 10.33978/2307-3586-2019-15-34-20-25

Речевые расстройства - одни из самых значимых и распространенных (до 42\% случаев) постинсультных когнитивных дебектов. В статье рассматриваются клинические проявления и диагностика постинсультных речевых нарушений. Особое внимание уделяется вопросам восстановления речи. Приводятся данные об эфбективности антагониста глутаматных NMDA-рецепторов мемантина у пациентов с постинсультной афазией.

Ключевые слова: инсульт, речевые нарушения, афазия, мемантин

\section{Введение}

Инсульт - чрезвычайно актуальная медико-социальная проблема ввиду широкой распространенности и высоких показателей инвалидизации и смертности. По данным регистра инсульта Научного центра неврологии, только 25\% больных после инсульта полностью независимы в повседневной жизни и трудоспособны [1]. Причиной инвалидизации после перенесенного инсульта наряду с двигательными и сенсорными расстройствами часто оказываются когнитивные нарушения, которые существенно ухудшают качество жизни пациента и членов его семьи. Одними из самых значимых и распространенных постинсультных когнитивных дефектов являются речевые расстройства. Они наблюдаются не менее чем у $42 \%$ больных, перенесших инсульт [2-5]. Речевые нарушения значительно ограничивают возможности социального взаимодействия, становятся причиной утраты профессиональных навыков, повышают экономические потери из-за затрат на лечение и нетрудоспособности. Они также негативно сказываются на возможностях коммуникации, в частности с медицинским персоналом, что снижает эффективность как двигательных, так и когнитивных реабилитационных мероприятий. Кроме того, постинсультные речевые расстройства сопряжены с высокой частотой депрессии, а по некоторым данным, и с увеличенным риском отсроченных летальных исходов и длительным пребыванием в стационаре $[2,4,6]$. В этой связи своевременные диагностика и коррекция нарушений речи у пациентов, перенесших инсульт, важное условие успешной реабилитационной программы.

\section{Классификация}

Постинсультные речевые нарушения включают различные виды афазий и дизартрий [7-9]. Несколько чаще в клинической практике встречается афазия - нарушение уже сформировавшейся речи, при котором частично или полностью утрачивается способность к вербальной коммуникации, включая построение собственного речевого высказывания и/или понимание обращенной речи при сохранности функции артикуляционного аппарата и слуха. В большинстве случаев афазия сопровождается нарушением письма и чтения (аграфией, алексией). Постинсультная афазия развивается при поражении доминантного по речи полушария, в подавляющем большинстве случаев левого (у правшей), но изредка (2-10\%) афазия наблюдается при поражении правого полушария [5]. Клиническая картина афазий зависит от локализации поражения в каждом конкретном случае $[7,8]$. Существуют так называемые речевые зоны мозга: задние отделы нижней лобной извилины, височные извилины, нижняя теменная область, а также зона, расположенная на стыке теменной, височной и затылочной областей доминантного (левого) полушария головного мозга. В клинической практике принято выделять несколько форм афазий.

Моторная эфберентная афазия (афазия Брока). Характеризуется трудностями инициации экспрессивной речи и переключения речевых программ. Клинически этот дефект проявляется персеверациями, которые затрудняют или делают совсем невозможной устную речь. Распадается грамматический строй: речь пациента разрывается паузами, он реже употребляет глаголы. Нарушается не только спонтанная речь, но и повторение слов, чтение вслух и письмо. Понимание речи сохранено. Данный вид афазии развивается при поражении задних отделов нижней лобной извилины доминантного полушария (зоны Брока) в результате инсульта в передних ветвях левой средней мозговой артерии, часто сочетается с гемипарезом и гемигипестезией. Сенсорная афазия (афазия Вернике - Кожевникова). Отличается утратой фонематического слуха (нарушение различения близких по звучанию созвучий, то есть 
фонем). Клинические особенности сенсорной афазии: отчуждение смысла слов, нарушение понимания обращенной речи. В менее грубых случаях пациентам трудно воспринимать слова с оппозиционными фонемами. Так, слово «голос» они слышат как «колос» или "холост». Спонтанная речь беглая, развернутая, эмоционально окрашенная, но непонятная для окружающих, поскольку содержит многочисленные замены слогов на близкие по звучанию, но бессмысленные по значению (литеральные парафазии). При значительной выраженности указанных расстройств речь приобретает характер так называемой словесной окрошки. Кроме того, у пациентов нарушены повторение услышанных слов, чтение и письмо. Сенсорная афазия развивается при поражении задних отделов верхней височной извилины доминантного полушария (зона Вернике - Кожевникова) обычно при инсульте в бассейне левой средней мозговой артерии. Она часто сочетается с правой верхнеквадрантной гемианопсией.

Сенсомоторная (тотальная) афазия. Развивается при одновременном поражении зоны Вернике Кожевникова и зоны Брока, поэтому в клинической картине имеют место признаки как сенсорной, так и моторной афазии. Является результатом обширных инсультов в левой средней мозговой артерии, обычно сочетается с гемипарезом, гемигипестезией и гемианопсией.

Динамическая абазия (транскортикальная моторная абазия). Как и эфферентная моторная афазия, проявляется речевым расстройством. В основе динамической афазии лежит нарушение инициации речевой активности, отмечаются грамматические ошибки и персеверации, в то время как понимание

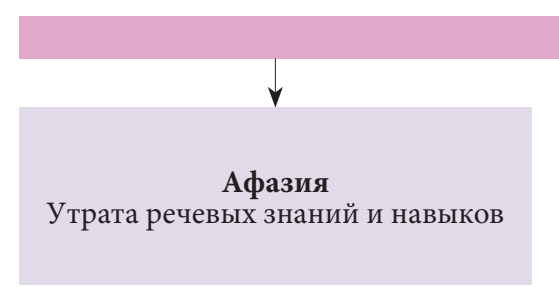

Основные типь речевых нарушений обращенной речи не страдает. В отличие от эфферентной моторной афазии при динамической афазии сохранена повторная речь: пациент может воспроизводить слова и фразы за врачом. Обычно динамическая афазия развивается при поражении премоторной области коры, примыкающей к зоне Брока, в результате инфаркта в бассейне левой передней мозговой артерии. Транскортикальная сенсорная абазия. Напоминает афазию Вернике Кожевникова, характеризуется неполным пониманием обращенной речи из-за трудностей распознавания грамматических отношений между словами в предложениях. Аналогичные трудности пациент испытывает при понимании прочитанного. Собственная речь пациентов беглая, но состоит из простых предложений, могут наблюдаться вербальные парафазии. В отличие от афазии Вернике - Кожевникова при транскортикальной сенсорной афазии повторная речь сохранена. Данный вид афазии развивается при поражении прилегающих к зоне Вернике теменно-затылочных областей, может сочетаться с гемианопсией.

Транскортикальная смешанная афазия. Имеет признаки транскортикальной моторной и сенсорной афазии. Важный диагностический критерий - сохранность повторной речи. Понимание письменной и устной речи существенно нарушено. Развивается при поражении префронтальных отделов лобных долей и зоны стыка височной, теменной и затылочной долей головного мозга при повторных церебральных эмболиях, инфарктах в зонах смежного кровоснабжения, связанных с системными циркуляторными нарушениями.

Амнестическая афазия. Характеризуется нарушением номинативной функции речи: пациент не может назвать показываемый предмет или сказать слово. Спонтанная речь сохраняет правильный грамматический строй, но значительно обедняется существительными, наблюдаются вербальные парафазии. Понимание речи, а также повторение слов и чтение вслух не нарушены. Амнестическая афазия может развиваться при повреждении различных анатомических зон: базальных отделов височной доли, передних отделов височной доли, височно-теменно-затылочного стыка, нижней теменной дольки $[9,10]$.

\section{Диагностика}

Предварительное впечатление о речевых нарушениях складывается в процессе обычного общения с пациентом при сборе жалоб и анамнеза. Важно провести дифференциальную диагностику между афазией и нарушениями артикуляции речи (дизартрией, дислалией) (рисунок). При исследовании речевого статуса принимается во внимание спонтанная речь пациента, определяется понимание обращенной речи, повторная речь, называние предметов, которые показывает врач, а также чтение и письмо.

Анализируя спонтанную речь, следует обращать внимание на ее беглость (среднее число слов в единицу времени), развернутый или односложный характер высказываний, грамматический и лексический строй (падежные окончания, предлоги, союзы, порядок слов в предложении и др.), немотивированные повторения отдельных слов и фраз (персеверации), литеральные и вербальные парафазии.

Понимание устной речи оценивается по выполнению пациентом устных команд, сначала простых («закройте ваши глаза», «покажите мне два пальца», «дотроньтесь правой 
рукой до левого уха»), а затем более сложных грамматических конструкций («Мамина дочка и дочкина мама - это один и тот же человек?», «Есть ли разница между выражениями „треугольник под кругом“ и „круг под треугольником“?»).

Для исследования номинативной функции речи пациенту показывают реальные предметы или их изображения, которые он должен назвать. Начинают с легких (например, ручка, расческа), потом переходят к более трудным (например, фонендоскоп). При недостаточности номинативной функции речи пациент может объяснить, что это за предмет и для чего он предназначен, но не может его назвать. Наиболее чувствительной методикой является бостонский тест называния.

При проверке функции чтения пациента просят прочитать вслух абзац из газеты или журнала, анализируя правильность произнесения слов. Понимание письменной речи проводится с помощью письменных команд (например, «закройте ваши глаза»). Для исследования письма пациента просят написать любое предложение. Кроме того, можно предложить написать простые или сложные слова, фразы под диктовку. В острый период инсульта помимо исследования речевого статуса большое значение имеет количественная и качественная оценка других высших мозговых функций: памяти, праксиса, гнозиса и др. [10].

\section{Прогноз}

Восстановление нарушений речи после инсульта - чрезвычайно сложная задача и зависит от множества факторов. У многих пациентов можно наблюдать спонтанный регресс речевых расстройств в течение первых нескольких месяцев после инсульта. Однако через год речевой дефект часто приобретает стойкий характер, и на его устранение может потребоваться от двух до шести и более лет $[2,5,7,8,11]$.

Большое число исследований посвящено изучению прогностических факторов регресса постинсультных речевых расстройств. Однако эти данные противоречивы, что, вероятно, объясняется различными ме- тодологическими подходами [2-4, 11-13]. Ключевое значение имеют локализация и объем повреждения вещества головного мозга. Например, поражение верхней височной извилины приводит к развитию стойкой тотальной афазии с неблагоприятным прогнозом [12]. При амнестической и тотальной афазии речевая функция восстанавливается хуже, чем при афазии Брока $[13,14]$. Ряд исследователей сообщают, что тяжесть исходной афазии негативно влияет на последующее восстановление речевой функции $[5,13,15]$. Другие авторы не обнаружили связи между регрессом речевых нарушений и клинической формой, а также исходной тяжестью афазии $[2,11]$.

Неблагоприятный прогноз для пациентов с речевыми расстройствами как в остром, так и восстановительном периоде инсульта обусловлен тяжестью очагового неврологического дефицита (устанавливается по шкале оценки тяжести инсульта Национального института здоровья США) и степенью функционального восстановления (определяется с помощью индекса Бартел). Тяжесть неврологической симптоматики один из факторов, ухудшающих процессы функциональной реорганизации нейрональных речевых сетей [2]. Биологические и социальные факторы (возраст, пол, образование) не имеют прогностического значения $[5,11,16]$, хотя в ряде исследований отмечено значимое влияние высокого уровня образования и молодого возраста на регресс афазии [2, 15].

Эмоциональное состояние сказывается на восстановлении речевого дефекта, но, по-видимому, также не является значимым прогностическим фактором [17]. Однако низкий уровень мотивации и вовлеченности пациента во время реабилитации ассоциируется с неблагоприятным прогнозом регресса речевых нарушений [18].

\section{Лечение}

Современные направления терапии постинсультных речевых нарушений подразумевают сочетание разных методов лечения и нейроре- абилитации, которые включают различные методики логопедической коррекции, протоколы ритмической транскраниальной магнитной стимуляции, а также фармакотерапию $[2,5$, 7, 8, 17, 19-21]. Выбор конкретного метода или сочетания методов восстановительной терапии определяется прежде всего тяжестью и клинической формой афазии.

\section{Немедикаментозные методы}

Логопедическая терапия, золотой стандарт лечения постинсультной афазии, представляет собой комплекс упражнений, направленных на различные аспекты функции речи в зависимости от доминирующего дефекта. По данным систематических обзоров, анализ эффективности логопедической терапии, включавшей различные методики, выявил снижение частоты афазии на $2-12 \%$ в течение первого года заболевания по сравнению с острым периодом ишемического инсульта $[2,4,19]$. Было показано, что конкретная методика логопедической коррекции не имеет принципиального значения, в то время как частота и интенсивность занятий достоверно влияют на прогноз [2, 19, 21]. Следует подчеркнуть, что максимальный отклик на логопедическую терапию отмечается в первые три месяца, в последующем эффективность проводимых мероприятий существенно снижается и после шести месяцев значительно падает $[11,21]$. К сожалению, в нашей стране реабилитация речевых нарушений проводится в недостаточном объеме, нередко ограничиваясь помощью в условиях стационара, что и определяет исход.

В последние десятилетия внедрение в клиническую и исследовательскую практику новейших методов нейровизуализации, таких как функциональная магнитнорезонансная томография, позволило существенно расширить представления об организации речевой системы в норме и исследовать пластичность мозга при регрессе постинсультной афазии in vivo на качественно ином струк- 
турном и функциональном уровне. Установлено, что в восстановительном периоде инсульта афазия регрессирует как за счет активации зон, непосредственно окружающих зону инфаркта или удаленных областей доминантного по речи левого полушария мозга, так и благодаря компенсаторной реорганизации симметричных структур правого полушария (гомологов речевых зон) [20, 22-24]. Согласно существующим представлениям, активация правосторонних гомологов речевых зон может положительно сказываться на восстановлении речи, носить компенсаторный характер или быть неэффективной, сдерживая функционирование и реализацию процессов нейропластичности левополушарной сети $[20,25]$. Эта патогенетическая модель легла в основу целого ряда исследований, направленных на подавление избыточного функционирования гомологов речевых зон правого полушария и стимуляцию речевых зон левого полушария при помощи транскраниальной магнитной стимуляции [24]. Наряду с решением научно-исследовательских задач ритмическая транскраниальная магнитная стимуляция используется в качестве достаточно эффективного метода восстановления речевых нарушений. Воздействие магнитного поля может оказывать локальное стимулирующее или ингибирующее влияние на отдельные участки коры, изменяя, таким образом, их функциональную активность и взаимодействие с другими зонами.

В ряде исследований курсовое лечение ритмической транскраниальной магнитной стимуляции в восстановительном периоде инсульта приводило к улучшению речи по сравнению с плацебо [20, 26]. Однако клиническая эффективность этого метода нуждается в дальнейшем изучении, поскольку в комплексе реабилитационных мероприятий у пациентов с постинсультной афазией ритмическая транскраниальная магнитная стимуляция, как правило, сочетается с медикаментозной терапией и логопедическими занятиями [27]. Это обусловливает поиск альтернативных стратегий в реабилитации пациентов с постинсультной афазией, причем важная роль отводится медикаментозной терапии.

\section{Медикаментозные методы}

Для восстановления когнитивных функций у пациентов с острыми нарушениями мозгового кровообращения в нашей стране широко используются препараты с вазоактивным, нейротрофическим, нейрометаболическим действием.

Регресс афазии после инсульта в результате применения селективных ингибиторов обратного захвата серотонина был продемонстрирован в нескольких клинических испытаниях. Селективные ингибиторы обратного захвата серотонина оказывают прямой положительный эффект на функцию речи, а также способствуют ее улучшению за счет уменьшения тревоги и депрессии, что позволяет пациентам более активно участвовать в речевой реабилитации [28, 29].

Были получены противоречивые результаты в отношении влияния дофаминергических средств на постинсультные речевые расстройства. Прием бромокриптина не сопровождался регрессом речевых нарушений. Терапия леводопой, напротив, оказывала положительное действие на речевые функции, но в сочетании с логопедическими упражнениями [30, 31].

Доказанное участие холинергических систем в реализации памяти, внимания и способности к обучению обосновывает перспективность использования холинергических препаратов в терапии постинсультной афазии. В открытом исследовании было продемонстрировано улучшение показателей речи на фоне применения галантамина по сравнению с плацебо, особенно при подкорковой локализации ишемических очагов [32].

По данным рандомизированного плацебоконтролируемого исследования, прием донепезила в дозе 10 мг ежедневно в комбинации с двухчасовой логопедической терапией еженедельно улучшал показатели номинативной функ- ции речи. Однако действие было краткосрочным и нивелировалось при дальнейшем наблюдении, тем самым свидетельствуя об исключительно симптоматическом эффекте терапии [33]. Поэтому подтверждение полученных положительных результатов требует последующих более крупных исследований.

NMDA-опосредованная эксайтотоксичность рассматривается в качестве одной из ведущих концепций гибели нейронов в зоне ишемической полутени [34]. Глутамат - возбуждающий медиатор, его выброс увеличивает энергозатраты постсинаптического нейрона. В условиях ишемии избыточная активация глутаматных рецепторов неизбежно приводит к истощению энергетических ресурсов нейрона, результатом чего становится нестабильность мембранного потенциала и гибель клетки. Ослабления активности глутаматергической системы можно добиться путем блокирования постсинаптических NMDA-рецепторов к глутамату. Однако эта блокада должна быть обратимой, поскольку нормальная передача возбуждения через глутаматергический синапс играет важную роль в обеспечении процессов памяти и внимания $[34,35]$.

Мемантин (Акатинол Мемантин) представляет собой обратимый блокатор постсинаптических NMDA-рецепторов к глутамату. Препарат способствует повышению порога генерации потенциала возбуждения постсинаптической мембраны, но не приводит к полной блокаде глутаматергического синапса, что лежит в основе его нейропротективного и симптоматического действия. В многочисленных клинических исследованиях продемонстрирована эффективность мемантина при болезни Альцгеймера, деменции с тельцами Леви, болезни Паркинсона и др. Были установлены хорошая переносимость препарата и отсутствие серьезных побочных эффектов [36, 37]. В ряде доклинических исследований выявлено, что мемантин может оказывать нейропротективное действие не только при нейродегенеративных деменциях, но и при церебральной ишемии 
[38, 39]. Проведено два длительных плацебоконтролируемых исследования (МММ-300 во Франции и МММ-500 в Великобритании), в которых лечение мемантином привело к улучшению когнитивных функций у пациентов с сосудистой деменцией $[40,41]$.

Эффективность Акатинола Мемантина в отношении постинсультных речевых нарушений продемонстрирована в работе Е.В. Лукьянюк и соавт., которые наблюдали 50 пациентов, перенесших инсульт в левом полушарии головного мозга 1-12 месяцев назад. Пациенты основной группы в составе комплексной нейрореабилитации (прием сосудистых средств, логопедические занятия, лечебная физкультура, массаж, рефлексотерапия) принимали Акатинол Мемантин в дозе 20 мг/сут в течение 90 дней. Контрольную группу составили десять пациентов, которые прошли курс нейрореабилитации и не получали Акатинол Мемантин. У большинства пациентов на второй-третьей неделе приема препарата отмечено улучшение показателей речи, регистрируемое логопедами. При этом значительное улучшение произошло у пациентов с сенсорной афазией. Авторы сделали вывод, что Акатинол Мемантин наиболее эффективен при максимально раннем назначении после инсульта в составе комплексной нейрореабилитации (на фоне активных логопедических занятий) [42].

В плацебоконтролируемом исследовании Акатинол Мемантин был назначен в позднем восстановительном периоде инсульта. Пациенты получали мемантин или плацебо в течение четырех месяцев. Затем в течение двух недель медикаментозное лечение сочеталось с логопедической терапией, далее следовал двухнедельный период, когда пациенты опять принимали только мемантин или плацебо. На фоне мемантина регистрировалось достоверное значительное улучшение показателей речи по сравнению с плацебо. Добавление к терапии логопедического тренинга улучшило показатели речевой функции в обеих группах, однако этот эффект был более заметным у пациентов, принимавших мемантин [43].

Полученные результаты подтвердились в аналогичном по дизайну исследовании. Использование вызванных потенциалов дает возможность показать достоверно более значимую активизацию корковых отделов и пораженного, и непораженного полушария в ответ на назначение мемантина. Положительный эффект мемантина сохранялся при дальнейшем наблюдении даже после отмены препарата, что позволяет рекомендовать Акатинол Мемантин к применению как в остром, так и восстановительном периоде инсульта [44].

\section{Заключение}

Лечение нарушений речи после инсульта должно быть комплексным и включать интенсивные логопедические занятия и медикаментозную терапию. Применение Акатинола Мемантина в комплексной терапии постинсультных речевых нарушений может способствовать восстановлению речевых функций.

\section{Литература}

1. Шахпаронова Н.В., Кадьков А.С. Постинсультные когнитивные нарушения. Возможности медикаментозной коррекции цитиколином (Цераксоном) // Нервные болезни. 2011. № 2. С. 16-19.

2. Алферова В.В., Шкловский В.М., Иванова Е.Г. идр. Прогноз постинсультной афазии // Журнал неврологии и психиатрии им. С.С. Корсакова. 2018. Т. 118. № 4. С. 20-29.

3. Plowman E., Hentz B., Ellis C.Jr. Post-stroke aphasia prognosis: a review of patient-related and stroke-related factors // J. Eval. Clin. Pract. 2012. Vol. 18. № 3. P. 689-694.

4. Flowers H.L., Skoretz S.A., Silver F.L. et al. Poststroke aphasia frequency, recovery, and outcomes: a systematic review and meta-analysis // Arch. Phys. Med. Rehabil. 2016. Vol. 97. № 12. P. 2188-2201.

5. Berthier M.L. Poststroke aphasia: epidemiology, pathophysiology and treatment // Drugs Aging. 2005. Vol. 22. № 2. P. 163-182.

6. Кутлубаев Н.А., Насретдинова А.Ф., Фаткуллина Л.К. u др. Депрессия у пациентов с постинсультной афазией: диагностика и клинические особенности // Практическая медицина. 2014. № 3. С. 103-106.

7. Шкловский В.М., Визель Т.Г. Восстановление речевой функции у больных с разными формами афазии. М.: Ассоциация дефектологов, 2000.

8. Цветкова Л.С. Афазия и восстановительное обучение. Учебное пособие. М.: МОДЭК; МПСИ, 2001.
9. Хомская М.Д. Нейропсихология. 4-е изд. СПб.: Питер, 2005. 10. Захаров В.В., Вознесенская Т.Г. Нервно-психические нарушения: диагностические тесты. М.: МЕДпрессинформ, 2013.

11. Watila M.M., Balarabe S.A. Factors predicting post-stroke aphasia recovery // J. Neurol. Sci. 2015. Vol. 352. № 1-2. P. 12-18.

12. Hanlon R.E., Lux W.E., Dromerick A.W. Global aphasia without hemiparesis: language profiles and lesion distribution // J. Neurol. Neurosurg. Psychiatry. 1999. Vol. 66. № 3. P. 365-369.

13. Pedersen P.M., Vinter K., Olsen T.S. Aphasia after stroke: type, severity, and prognosis // Cerebrovasc. Dis. 2004. Vol. 17. № 1. P. 35-43.

14. Jung I.Y., Lim J.Y., Kang E.K. et al. The factors associated with good responses to speech therapy combined with transcranial direct current stimulation in post-stroke aphasic patients // Ann. Rehabil. Med. 2011. Vol. 35. № 4. P. 460-469.

15. Pedersen P.M., Jørgensen H.S., Nakayama H. et al. Aphasia in acute stroke: incidence, determinants, and recovery // Ann. Neurol. 1995. Vol. 38. № 4. P. 659-656.

16. Lazar R.M., Speizer A.E., Festa J.R. et al. Variability in language recovery after first-time stroke // J. Neurol. Neurosurg. Psychiatry. 2008. Vol. 79. № 5. P. 530-534.

17. Robey R.R. A meta-analysis of clinical aphasia outcomes in the treatment of aphasia // J. Speech Lang. Hear. Res. 1998. Vol. 41. № 1. P. 172-187.

18. Code C., Herrmann M. The relevance of emotional and psychological factors in aphasia to rehabilitation // Neuropsychol. Rehabil. 2003. Vol. 13. № 1-2. P. 109-132. 
19. Brady M.C., Kelly H., Godwin J. et al. Speech and language therapy for aphasia following stroke // Cochrane Database Syst. Rev. 2016. Vol. 6. CD000425.

20. Белопасова А.В., Кадьков А.С., Червяков А.В., Белопасов В.В. Диагностический и лечебный потенциал транскраниальной магнитной стимуляции при афазии // Неврологический журнал. 2015. Т. 20. № 4. С. 23-28.

21. Mattioli F. The clinical management and rehabilitation of post stroke aphasia in Italy: evidences from the literature and clinical experience // Neurol. Sci. 2019. Vol. 40. № 7. P. 1329-1334.

22. Fridriksson J., Richardson J.D., Fillmore P., Cai B. Left hemisphere plasticity and aphasia recovery // Neuroimage. 2012. Vol. 60. № 2. P. 854-863.

23. Hickok G., Poeppel D. The cortical organization of speech processing // Nat. Rev. Neurosci. 2007. Vol. 8. № 5. P. 393-402.

24. Алферова В.В., Майорова Л.А., Иванова Е.Г. и др. Функциональная нейровизуализация структур мозга, связанных с речью, в норме и при постинсультной афазии // Журнал неврологии и психиатрии им. С.С. Корсакова. 2017. Т. 117. № 3-2. C. 71-78.

25. Thulborn K.R., Carpenter P.A., Just M.A. Plasticity of language-related brain function during recovery from stroke // Stroke. 1999. Vol. 30. № 4. P. 749-754.

26. Kindler J., Schumacher R., Cazzoli D. et al. Theta burst stimulation over the right Broca's homologue induces improvement of naming in aphasic patients // Stroke. 2012. Vol. 43. № 8. P. 2175-2179.

27. Червяков А.В., Пойдашева А.Г., Коржова Ю.Е. и др. Современные терапевтические возможности ритмической транскраниальной магнитной стимуляции в лечении заболеваний нервной системы // РМЖ. 2014. T. 22. № 22. C. 1567-1572.

28. Li W.L., Cai H.H., Wang B. et al. Chronic fluoxetine treatment improves ischemia-induced spatial cognitive deficits through increasing hippocampal neurogenesis after stroke // J. Neurosci. Res. 2009. Vol. 87. № 1. P. 112-122.

29. Laska A.C., von Arbin M., Kahan T. et al. Long-term antidepressant treatment with moclobemide for aphasia in acute stroke patients: a randomised, double-blind, placebo-controlled study // Cerebrovasc. Dis. 2005. Vol. 19. № 2. P. 125-132.

30. Ashtary F., Janghorbani M., Chitsaz A. et al. A randomized, double-blind trial of bromocriptine efficacy in nonfluent aphasia after stroke // Neurology. 2006. Vol. 66. № 6. P. 914-916.

31. Bakheit A.M. Drug treatment of poststroke aphasia // Expert Rev. Neurother. 2004. Vol. 4. № 2. P. 211-217.
32. Hong J.M., Shin D.H., Lim T.S. et al. Galantamine administration in chronic post-stroke aphasia // J. Neurol. Neurosurg. Psychiatry. 2012. Vol. 83. № 7. P. 675-680.

33. Berthier M.L., Green C., Higueras C. et al. A randomized, placebo-controlled study of donepezil in poststroke aphasia // Neurology. 2006. Vol. 67. № 9. P. 1687-1689.

34. Martin H.G., Wang Y.T. Blocking the deadly effects of the NMDA receptor in stroke // Cell. 2010. Vol. 140. № 2. P. 174-176.

35. Mark L.P., Prost R.W., Ulmer J.L. et al. Pictorial review of glutamate excitotoxicity: fundamental concepts for neuroimaging // AJNR Am. J. Neuroradiol. 2001. Vol. 22. № 10. P. 1813-1824.

36. Reisberg B., Doody R., Stöffler A. et al. Memantine in moderate-to-severe Alzheimer's disease // N. Engl. J. Med. 2003. Vol. 348. № 14. P. 1333-1341.

37. Aarsland D., Ballard C., Walker Z. et al. Memantine in patients with Parkinson's disease dementia or dementia with Lewy bodies: a double-blind, placebo-controlled, multicentre trial // Lancet Neurol. 2009. Vol. 8. № 7. P. 613-618.

38. Francis P.T. Behavioral effects of memantine: understanding the pharmacological rationale // Eur. J. Neurology. 2007. Vol. 14. Suppl. Abstract P2098.

39. Левин О.С., Васенина Е.Е. Применение Акатинола Мемантина в клинической практике // Современная терапия в психиатрии и неврологии. 2015. № 1. С. 24-33.

40. Orgogozo J.M., Rigaud A.S., Stöffler A. et al. Efficacy and safety of memantine in patients with mild to moderate vascular dementia: a randomized, placebo-controlled trial (MMM 300) // Stroke. 2002. Vol. 33. № 7. P. 1834-1839.

41. Wilcock G., Möbius H.J., Stöffler A. A double-blind, placebocontrolled multicentre study of memantine in mild to moderate vascular dementia (MMM500) // Int. Clin. Psychopharmacol. 2002. Vol. 17. № 6. P. 297-305.

42. Лукьянюк Е.В., Малюкова Н.Г., Шкловский В.М. и др. Опыт применения акатинола мемантина в резидуальном периоде инсульта // Журнал неврологии и психиатрии им. С.С. Корсакова. 2010. Т. 110. № 12. С. 28-33.

43. Berthier M.L., Green C., Lara J.P. et al. Memantine and constraint-induced aphasia therapy in chronic poststroke aphasia // Ann. Neurol. 2009. Vol. 65. № 5. P. 577-585.

44. Barbancho M.A., Berthier M.L., Navas-Sánchez P. et al. Bilateral brain reorganization with memantine and constraint-induced aphasia therapy in chronic post-stroke aphasia: an ERP study // Brain Lang. 2015. Vol. 145-146. P. 1-10.

\section{Speech Recovery After Stroke}

D.A. Grishina, $\mathrm{PhD}$

I.M. Sechenov First Moscow State Medical University

Contact person: Dinara A. Grishina, dstepkina@mail.ru

Speech disorders is one of the most significant and common (up to $42 \%$ of cases) post-stroke cognitive defects. The article discusses the clinical manifestations and diagnosis of post-stroke speech disorders. Special attention is being paid to the issues of speech recovery. Data on the efficacy of memantine glutamate NMDA receptor antagonist in patients with post-stroke aphasia are provided.

Key words: stroke, speech disorders, aphasia, memantine 